\title{
Viabilidade Celular de Nanofibras de Polímeros Biodegradáveis e seus Nanocompósitos com Argila Montmorilonita
}

\author{
Alfredo M. Goes \\ Instituto de Ciências Biológicas, UFMG \\ Sandhra Carvalho, Rodrigo L. Oréfice \\ Departamento de Engenharia Metalúrgica e de Materiais, UFMG
}

Luc Avérous

Laboratoire d'Ingénierie des Polymères pour les Hautes Technologies, Université de Strasbourg

Tassiana A. Custódio, Jeferson G. Pimenta, Matheus de B. Souza, Marcia C. Branciforti, Rosario E. S. Bretas

Departamento de Engenharia de Materiais, UFSCar

Resumo: Mantas não tecidas de nanofibras de três polímeros biodegradáveis poli(ácido láctico), PDLLA, poli(ع-caprolactona), PCL, e poli(butileno adipato-co-tereftalato), PBAT e seus nanocompósitos com uma nanoargila montmorilonita (MMT) foram produzidas por eletrofiação. A morfologia, o comportamento térmico e a estrutura interna das nanofibras foram analisados por microscopia eletrônica de varredura e transmissão, calorimetria diferencial de varredura e difração de raios X, respectivamente. Observou-se que as nanofibras dos nanocompósitos possuíam diâmetros menores do que os correspondentes polímeros puros e que as nanofibras de PBAT puro e de PBAT/MMT apresentavam a menor cristalinidade de todas as mantas. A viabilidade celular de todas as nanofibras foi analisada pela técnica de redução do sal de tetrazolium pelo complexo enzimático piruvato desidrogenase presente na matriz de mitocôndrias (teste MTT). Os resultados mostraram que nenhuma manta nanofibrílica apresentou toxicidade às células e que as nanofibras de PBAT puro e seu nanocompósito propiciaram ainda um ambiente mais favorável ao desenvolvimento celular de fibroblastos de cardiomiócitos do que as condições oferecidas pelo controles, provavelmente por apresentarem menores diâmetros e baixa cristalinidade em relação às demais nanofibras. Estes resultados mostram o potencial de uso destas mantas nanofibrílicas como suportes de crescimento celular.

Palavras-chave: Viabilidade celular, nanofibras, eletrofiação, nanocompósitos, polímeros biodegradáveis.

\section{Cell Viability of Nanofibers from Biodegradable Polymers and their Nanocomposites with Montmorillonite}

\begin{abstract}
Non-woven mats of nanofibers of three biodegradable polymers, viz. poly(lactic acid), PDLLA, poly( $(\varepsilon$-caprolactone), PCL, and poly(butylene adipate-co-terephthalate), PBAT, and their nanocomposites with montmorillonite nanoclay (MMT) were produced by electrospinning. The morphology, thermal behavior and internal structure of the nanofibers were analyzed by scanning and transmission electron microscopy, differential scanning calorimetry and wide angle X-ray diffraction, respectively. The nanofibers of the nanocomposites had lower diameters than the nanofibers of the corresponding neat polymers, while the nanofibers from PBAT and PBAT/MMT were the least crystalline. The cell viability of all the nanofibers was analyzed by reduction of the tetrazolium salt by the pyruvate dehydrogenase enzymatic complex present in the mitochondria (MTT test). None of the nanofibers was toxic to the cells and the PBAT and PBAT/MMT nanofibers exhibited a more favorable environment for developing fibroblasts from cardiomyocytes than the control, probably due to their low crystallinity. These results demonstrated the potential use of nanofibers' mats as scaffolds for cell growth.
\end{abstract}

Keywords: Cell viability, nanofibers, electrospinning, nanocomposites, biodegradable polymers.

\section{Introdução}

Nanofibras de polímeros podem ser facilmente produzidas pelo processo de eletrofiação, desde que os polímeros tenham uma boa solubilidade em solventes. Na eletrofiação, uma solução polimérica é colocada num tubo capilar dentro do qual é inserido um eletrodo metálico ligado a uma fonte de alta tensão elétrica e o coletor está devidamente aterrado. Quando o campo elétrico aplicado (tensão elétrica/distância entre capilar e coletor) atinge um valor critico, o cone de solução polimérica formado na ponta do capilar transforma-se num jato que, devido às instabilidades viscoelásticas, forma as nanofibras após evaporação do solvente, sendo estas depositadas no coletor na forma de mantas não tecidas e de elevada área superficial ${ }^{[1]}$.

Materiais inorgânicos em escala nanométrica podem apresentar diferentes propriedades físicas, dando origem a novas aplicações nas áreas de biofármacos, agentes de liberação controlada de drogas e biossensores. No entanto, uma preocupação geral é que esses novos nanomateriais devem ser avaliados quanto à sua segurança para o ambiente e sua bioabsortividade ${ }^{[2]}$. Dentre os nanomateriais, os minerais naturais de silicatos, tais como argila montmorilonita sódica (MMT) são considerados materiais seguros. Desenvolvimentos recentes sobre as argilas têm ampliado sua aplicação além das convencionais como nanocompósitos, adsorventes e catalisadores. Novas aplicações para argilas têm avançado para muitas aplicações biomédicas incluindo sistemas de liberação controlada de drogas, agentes hemostáticos e agente antibacteriano, sendo concluído que a MMT pode ser considerada segura para uma infinidade de aplicações ${ }^{[3-7]}$.

Autor para correspondência: Rosário E. S. Bretas, Departamento de Engenharia de Materiais, Universidade Federal de São Carlos, 
Suportes poliméricos para produção de tecidos do corpo humano devem ter uma série de pré-requisitos ${ }^{[8]}$ como porosidade elevada, uma química superficial que permita a adesão, crescimento e diferenciação das células e uma taxa de degradação similar à taxa de regeneração do tecido. Adicionalmente devem ter a mesma estrutura ou topologia da matriz extracelular. Nanofibras produzidas por eletrofiação possuem a mesma estrutura e topologia que as matrizes extracelulares naturais, assim são candidatas ideais para a produção destes suportes. Porém, os efeitos que uma matriz artificial possa ter neste crescimento, diferenciação e proliferação das células ainda precisam ser amplamente investigados ${ }^{[9]}$.

Neste trabalho nanofibras de três polímeros biodegradáveis e seus nanocompósitos com uma nanoargila MMT foram produzidas por eletrofiação. $\mathrm{O}$ comportamento das nanofibras na toxicidade às células e no crescimento das mesmas foi estudado.

\section{Experimental}

\section{Materiais}

A Tabela 1 apresenta os nomes dos fabricantes e algumas propriedades dos polímeros biodegradáveis utilizados. No caso de nanocompósitos de polímeros biodegradáveis, a nanocarga utilizada foi a argila montmorilonita (MMT) de nome comercial Cloisite $^{\circledR} 30 \mathrm{~B}$, da Southern Clay Products (USA), tratada com surfactante orgânico MT2EtOH (sal quaternário de amônia, metil cauda bis-2-hidroxietil).

\section{Preparação e caracterização das soluções poliméricas}

As soluções poliméricas foram preparadas utilizando os seguintes solventes: dimetilformamida (DMF), clorofórmio $(\mathrm{Cl})$, acetona (A) e metanol (MeOH), todos com pureza P.A, da Synth. As seguintes soluções foram preparadas:

\section{Amostra 3}

Soluções de $7 \% \mathrm{~m} \cdot \mathrm{v}^{-1}$ de PDLLA em 60/40 v. $\mathrm{v}^{-1} \mathrm{Cl} / \mathrm{DMF}$ foram preparadas dissolvendo primeiro o PDLLA no clorofórmio e depois adicionando o DMF, utilizando um banho aquecido a $40{ }^{\circ} \mathrm{C}$ como descrito $\mathrm{em}^{[11]}$.

\section{Amostra 4}

Soluções de $10 \% \mathrm{~m} . \mathrm{v}^{-1}$ de PDLLA em 60/40 v.v ${ }^{-1} \mathrm{Cl} / \mathrm{A}$ foram preparadas dissolvendo primeiro o PDLLA no clorofórmio e depois adicionando a acetona, utilizando um banho aquecido a $40{ }^{\circ} \mathrm{C}$ como descrito $\mathrm{em}^{[11]}$.

Tabela 1. Polímeros biodegradáveis utilizados.

\begin{tabular}{|c|c|c|c|}
\hline Polímero & Sigla & Fabricante & Propriedades \\
\hline $\begin{array}{c}\text { Poli(ácido láctico) } \\
\text { (92\% L-lactidio e 8\% } \\
\text { isómero meso-lactidio) }\end{array}$ & PDLLA & $\begin{array}{l}\text { Nature-Works } \\
\text { (USA) }\end{array}$ & $\begin{array}{c}\mathrm{M}_{\mathrm{w}}=186,000 \mathrm{~g} \cdot \mathrm{mol}^{-1} \\
\mathrm{M}_{\mathrm{n}}=106,000 \mathrm{~g} \cdot \mathrm{mol}^{-1} \\
\mathrm{~T}_{\mathrm{g}}=57^{\circ} \mathrm{C} \\
\mathrm{T}_{\mathrm{m}}=152^{\circ} \mathrm{C}\end{array}$ \\
\hline Poli(E-caprolactona) & PCL & $\begin{array}{l}\text { Solvay } \\
\text { (CAPA6430) } \\
\text { (Bélgica) }\end{array}$ & $\begin{array}{c}\mathrm{M}_{\mathrm{n}}=43000 \mathrm{~g} \cdot \mathrm{mol}^{-1} \\
\mathrm{~T}_{\mathrm{m}}=58-60^{\circ} \mathrm{C}\end{array}$ \\
\hline $\begin{array}{l}\text { Poli(butileno adipato- } \\
\text { co-tereftalato) }\end{array}$ & PBAT & $\begin{array}{c}\text { BASF } \\
\text { (Alemanha) }\end{array}$ & $\mathrm{T}_{\mathrm{m}}=110-120^{\circ} \mathrm{C}$ \\
\hline $\begin{array}{l}\text { Surfactante da argila } \\
\text { montmorilonita }\end{array}$ & MT2EtOH & $\begin{array}{l}\text { Southern } \\
\text { Clay Products } \\
\text { (USA) }\end{array}$ & $\begin{array}{c}\mathrm{T}_{\mathrm{d}}=275^{\circ} \mathrm{C} \\
\mathrm{c}=900 \mathrm{Meq} \cdot \mathrm{kg}^{-1}\end{array}$ \\
\hline
\end{tabular}

$\mathrm{M}_{\mathrm{w}}=$ peso molecular médio ponderal; $\mathrm{M}_{\mathrm{n}}=$ peso molecular médio numérico; $\mathrm{T}_{\mathrm{g}}=$ temperatura de transição vítrea; $\mathrm{T}_{\mathrm{m}}=$ temperatura de

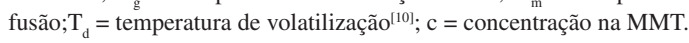

\section{Amostra 5}

A PCL $\left(15 \% \mathrm{~m} \cdot \mathrm{v}^{-1}\right)$ e a argila organofílica Cloisite ${ }^{\circledR}$ 30B $\left(2,5 \% \mathrm{~m} \cdot \mathrm{v}^{-1}\right)$ foram dissolvidas primeiramente em clorofórmio a temperatura ambiente e sob agitação constante; posteriormente o metanol foi adicionado na proporção de $75 / 25 \mathrm{v} \cdot \mathrm{v}^{-1} \mathrm{Cl} / \mathrm{MeOH}$. Após a dissolução, as soluções de PCL e Cloisite ${ }^{\circledR}$ 30B foram mantidas durante 5 horas em um aparelho de ultra-som sob agitação. A concentração final da solução estudada foi de $15 \% \mathrm{~m} \cdot \mathrm{v}^{-1}$ PCL com 2,5\% m.v $\mathrm{v}^{-1}$ Cloisite $^{\circledR} 30 \mathrm{~B}$.

\section{Amostra 6}

A PCL (15\% m. $\left.\mathrm{v}^{-1}\right)$ foi dissolvida primeiramente em clorofórmio a temperatura ambiente e sob agitação constante; posteriormente o metanol foi adicionado na proporção de $75 / 25$ v.v ${ }^{-1} \mathrm{Cl} / \mathrm{MeOH}$. Após a dissolução, a solução de PCL foi mantida durante 5 horas em um aparelho de ultra-som sob agitação. A concentração final da solução foi de $15 \%$ m. $\mathrm{v}^{-1} \mathrm{PCL}$, como recentemente descrito ${ }^{[10]}$.

\section{Amostra 7}

A PCL $\left(20 \% \mathrm{~m} \cdot \mathrm{v}^{-1}\right)$ foi dissolvida primeiramente em clorofórmio a temperatura ambiente e sob agitação constante; em seguida o metanol foi adicionado na proporção de $75 / 25$ v.v ${ }^{-1} \mathrm{Cl} / \mathrm{MeOH}$. Após a dissolução, a solução de PCL foi mantida durante 5 horas em um aparelho de ultra-som sob agitação, sendo que a concentração final da solução foi de $20 \% \mathrm{~m} . \mathrm{v}^{-1} \mathrm{PCL}$, como recentemente descrito ${ }^{[10]}$.

Amostra 8

O PBAT puro foi primeiramente dissolvido em clorofórmio e depois foi acrescentado DMF na proporção de 85/15 v.v ${ }^{-1}$ clorofórmio/DMF. A concentração de PBAT final foi de $10 \% \mathrm{~m} \cdot \mathrm{v}^{-1}$.

\section{Amostra 9}

No caso desta amostra foi preparado um nanocompósito de PBAT com a nanoargila ( $2 \%$ em massa) por mistura no fundido utilizando um reômetro de torque Haake, modelo Rheomics 610, com um par de rotores contra-rotacionais e semi-interpenetrantes. As condições de processamento utilizadas foram: temperatura de processamento de $180{ }^{\circ} \mathrm{C}$, rotação de $50 \mathrm{rpm}$ e tempo que o material permaneceu dentro da câmara de 5 minutos. Para preparação da solução, o nanocompósito foi primeiramente dissolvido em $\mathrm{Cl}$ e depois foi adicionado DMF, na proporção de 90/10 v.v ${ }^{-1}$ Cl/DMF. A concentração final da solução de nanocompósito foi de $10 \% \mathrm{~m} \cdot \mathrm{v}^{-1}$ em PBAT e $2 \%$ m.v $v^{-1}$ em MMT.

\section{Eletrofiação das soluções poliméricas}

A eletrofiação de todas as soluções poliméricas foi feita por meio de sistema composto por uma fonte de alta tensão Bertan modelo 30-R ou em alguns casos uma fonte Glassman, modelo EH30P3, um coletor cilíndrico rotatório coberto com folhas de alumínio e aterrado (girando entre 20 e $40 \mathrm{rpm}$ ), uma seringa de vidro de $20 \mathrm{~mL}$ com agulha tipo Hamilton com diâmetro interno e comprimento variáveis (dependendo da viscosidade da solução) e um eletrodo de cobre, de acordo com a Figura $1^{[12]}$.

Todas as mantas foram eletrofiadas a $25 \pm 2{ }^{\circ} \mathrm{C}$ e com umidade ambiental controlada de $50 \pm 5 \%$. A Tabela 2 mostra as condições de eletrofiação de cada amostra.

\section{Caracterização morfológica das mantas nanofibrilicas}

A morfologia das mantas nanofibrilicas foi analisada por microscopia eletrônica de varredura (MEV) utilizando um microscópio Phillips ${ }^{\circledR}$ modelo FEG XL30 operando a 10 kV. Em alguns casos, a microscopia eletrônica de transmissão (MET) também foi utilizada; o equipamento foi um microscópio Phillips ${ }^{\circledR}$, 


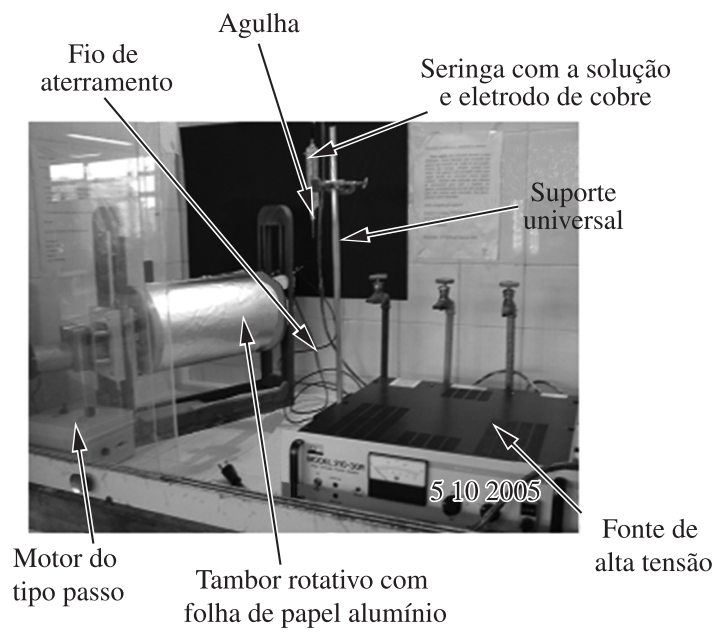

Figura 1. Sistema de eletrofiação ${ }^{[12]}$.

Tabela 2. Condições de eletrofiação das amostras e diâmetro médio das nanofibras.

\begin{tabular}{cccc}
\hline Amostra & $\begin{array}{c}\text { Diâmetro } \\
\text { interno }(\mathbf{m m}) / \mathbf{e} \\
\text { comprimento }(\mathbf{m m}) \\
\text { da agulha }\end{array}$ & $\begin{array}{c}\text { Campo elétrico } \\
\left(\mathbf{k V . c m}^{-1}\right)\end{array}$ & $\begin{array}{c}\text { Diâmetro } \\
\text { médio das } \\
\text { nanofibras } \\
(\mathbf{n m})\end{array}$ \\
\hline 3 & $1,5 / 30$ & 1,5 & $178 \pm 85$ \\
4 & $1,5 / 30$ & 1,5 & $1463 \pm 549$ \\
5 & $0,8 / 30$ & 2,6 & $281 \pm 54$ \\
6 & $1,5 / 30$ & 1,1 & $340 \pm 119$ \\
7 & $1,5 / 30$ & 1,5 & $1125 \pm 155$ \\
8 & $1,5 / 30$ & 1,5 & $980 \pm 250$ \\
9 & $1,5 / 30$ & 2,0 & $175 \pm 68$ \\
\hline
\end{tabular}

modelo CM120, operando a 120 kV. O diâmetro médio das fibras (aproximadamente 100-120 fibras/amostra) foi calculado utilizando o software Image Pro-Plus 4.5.

\section{Caracterização térmica e estrutural das mantas}

A caracterização térmica das mantas nanofibrilicas foi feita por calorimetria diferencial de varredura (DSC) utilizando equipamento marca TA Instruments, modelo Q100, e taxas de aquecimento e resfriamento de $10{ }^{\circ} \mathrm{C} / \mathrm{min}$. As mantas de PCL foram secas primeiramente em estufa à vácuo a $30{ }^{\circ} \mathrm{C}$ por um período de 24 horas. As outras mantas foram analisadas sem pré-secagem. A percentagem de cristalinidade $\left(\mathrm{X}_{\mathrm{c}}\right)$ do polímero foi calculada utilizando a relação:

$$
X_{c}=\frac{\Delta H_{m}-\Delta H_{c c}}{\Delta H_{m}^{o}} \times 100
$$

na qual $\Delta \mathrm{H}_{\mathrm{m}}$ é a entalpia de fusão da amostra, $\Delta \mathrm{H}_{\mathrm{cc}}$ é a entalpia de cristalização a frio da amostra, e $\Delta \mathrm{H}_{\mathrm{m}}$ é a entalpia de fusão teórica de uma amostra $100 \%$ cristalina. No caso do PDLLA, $\Delta \mathrm{H}_{\mathrm{m}}^{0}=93 \mathrm{~J}^{\mathrm{J}} \mathrm{g}^{-1[13]}$, do PBAT é $114 \mathrm{~J}_{\mathrm{g}} \mathrm{g}^{-1[14]}$ e do PCL é $139,5 \mathrm{~J} \cdot \mathrm{g}^{-1[15]}$. A percentagem aproximada de solvente residual $\left(\mathrm{X}_{\mathrm{sr}}\right)$ nas mantas nanofibrílicas foi calculada pela relação:

$$
X_{s r}=\frac{m}{m_{T}} \times 100
$$

onde $\mathbf{m}$ é a massa do solvente residual (em $\mathrm{kg}$ ) e $\mathbf{m}_{\mathrm{T}}$ é a massa da amostra no DSC (em $\mathrm{kg}$ ). A massa $\mathbf{m}$ foi calculada a partir da endoterma de vaporização do solvente, $\Delta \mathrm{H}_{\mathrm{v}}$, já que:

$$
\Delta H_{v}=m(c \Delta T+L)
$$

onde c é o calor especifico do solvente, $\Delta \mathrm{T}$ é a temperatura de vaporização final - temperatura de vaporização inicial no termograma do DSC e L é o calor latente de vaporização do solvente. No caso de ter-se uma mistura de solventes, os valores de $\mathbf{c}$ e $\mathbf{L}$ foram calculados utilizando a lei das misturas como aproximação, ou seja:

$$
\begin{aligned}
& c \cong \bar{c}=c_{1} x_{1}+c_{2} x_{2} \\
& \mathrm{e} \\
& L \cong \bar{L}=L_{1} x_{1}+L_{2} x_{2}
\end{aligned}
$$

onde $c_{1}$ e $c_{2}$ são os calores específicos dos solventes 1 e 2, respectivamente, $\mathrm{L}_{1}$ e $\mathrm{L}_{2}$ são os calores latentes de vaporização dos solventes 1 e 2 , respectivamente, e $\mathrm{x}_{1}$ e $\mathrm{x}_{2}$ representam as frações volumétricas dos solventes 1 e 2 respectivamente.

Analise de difração de raios-X de alto ângulo (DRX) da MMT e do nanocompósito de PCL foi realizada em um difratômetro Siemens, modelo D5000, com radiação $\mathrm{CuK} \alpha(\lambda=1,5458 \AA)$ filtrada por $\mathrm{Ni}$ no modo reflexão a $40 \mathrm{kV}$ e $40 \mathrm{~mA}$. Nas mantas de nanocompósito de PBAT o difratômetro utilizado foi Rigaku, modelo Multiflex, no modo reflexão a $30 \mathrm{kV}$ e $10 \mathrm{~mA}$. Os difratogramas foram obtidos na faixa de $2 \theta$ de 0,8 a $10^{\circ}$.

\section{Testes de viabilidade celular}

Foi utilizada a técnica de redução do sal de tetrazolium (MTT) pelo complexo enzimático piruvato desidrogenase presente na matriz de mitocôndrias. Esse complexo enzimático transforma o sal de tetrazolium em produtos finais de metabolização chamados de cristais de formazan que podem depois serem mensurados quantitativamente em espectrofotômetro a $595 \mathrm{~nm}$. Esse ensaio deve ser usado especificamente para a funcionalidade mitocondrial. A mitocôndria é uma das organelas celulares mais importantes, uma vez que é responsável pela respiração celular, portanto a quantificação de sua viabilidade leva indiretamente a viabilidade da célula. As células geralmente apresentam número variável de mitocôndrias, sendo proporcional à atividade metabólica de cada célula, podendo variar de quinhentas até dez mil por célula. Portanto, o resultado pode significar um aumento da atividade enzimática por um número menor de células do que realmente o gráfico demonstra.

\section{Experimento 1:}

As mantas nanofibrílicas foram colocadas em lamínulas de vidro com 0,17 $\mathrm{mm}$ de espessura (Fisherbrand/Microscope Cover Glass) e esterilizadas com lâmpada ultra violeta (UV) por trinta minutos em cada lado da lamínula. Após esse período, as mesmas foram colocadas em placas de 24 wells. Foram colocados $500 \mu \mathrm{L}$ de meio DMEM (Dulbecco's Modified Eagle Medium/ GIBCO, N.Y, USA) em cada poço e foram semeadas $1 \times 10^{4}{\text { células. } \mathrm{cm}^{-3}}^{-3}$ de células SkHep (células da linhagem adeno hepático-carcinômica humana). As células foram mantidas por 24 horas com meio DMEM sem soro em estufa com $5 \%$ de $\mathrm{CO}_{2}$ a $37{ }^{\circ} \mathrm{C}$. Esse procedimento foi realizado para as células serem normalizadas em relação ao crescimento e proliferação celular. Após esse período o meio foi aspirado e trocado por DMEM com 10\% de soro fetal bovino (SFB), exceto, no controle sem a presença de soro fetal bovino (neste caso foi colocado novamente DMEM puro, sem soro fetal bovino). Foram criadas assim as populações $3,4,5,6,7,8$, e 9 de amostras de mantas nanofibrílicas, uma população controle com (SFB) e outra como controle sem (SFB); todos os testes foram realizados em triplicatas. Foram utilizados como controle positivo PBS (solução tampão de fosfato $2 \mathrm{X}$, ou seja, com o dobro das concentrações dos sais) e como controle negativo lamínulas de vidro de $0,17 \mathrm{~mm}$ de espessura. 
Após 72 horas todo o meio foi aspirado e foram colocados $210 \mu \mathrm{L}$ de meio de cultura com soro em cada poço. Foram acrescentados $170 \mu \mathrm{L}$ de MTT (5 mg. $\mathrm{mL}^{-1} ; 5 \mathrm{mg} \cdot \mathrm{mL}^{-1}$; SIGMAALDRICH, USA) em cada poço e as placas incubadas por 4 horas em estufa a $37{ }^{\circ} \mathrm{C}$ e $5 \%$ de $\mathrm{CO}_{2}$. Em seguida foram colocados $210 \mu \mathrm{L}$ de solução de isopropanol/4\% HCl. Após 10 minutos foram retirados $100 \mu \mathrm{L}$ de cada poço e transferidos para placa de 96 poços plana e a quantificação foi feita em espectrofotômetro (ADAP 1.6, Anthos Labtec Instruments) com filtro de $595 \mathrm{~nm}$. Os experimentos foram realizados com $n=3$ e os dados analisados com a ajuda do programa PRISM (Test One-way- Bonferroni/GraphPad, San Diego, CA, USA).

\section{Experimento 2}

O protocolo foi idêntico ao do experimento 1, porém, as células utilizadas foram de cultura primária de fibroblastos de cardiomiócitos de neonatos de ratos Wistar. Foram criadas assim 11 populações de teste realizados em triplicatas:

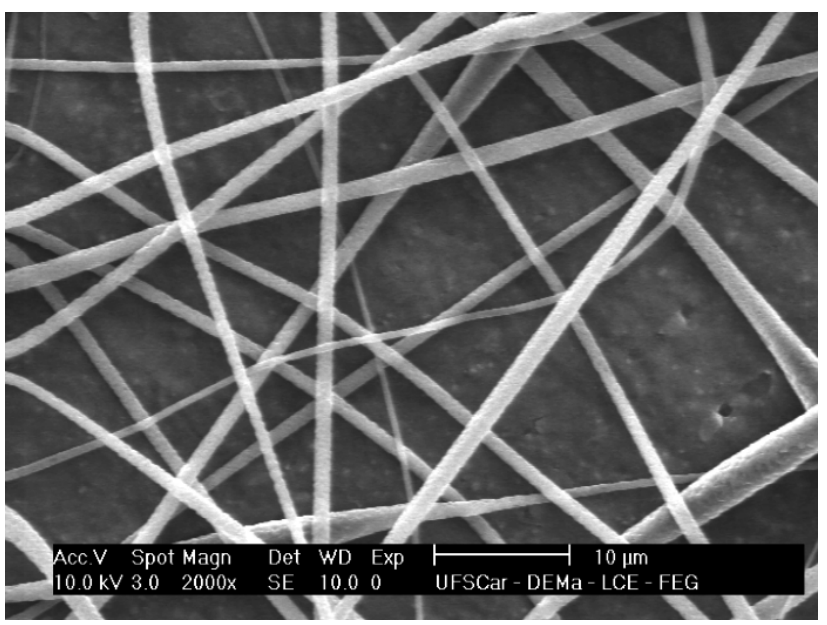

(a)

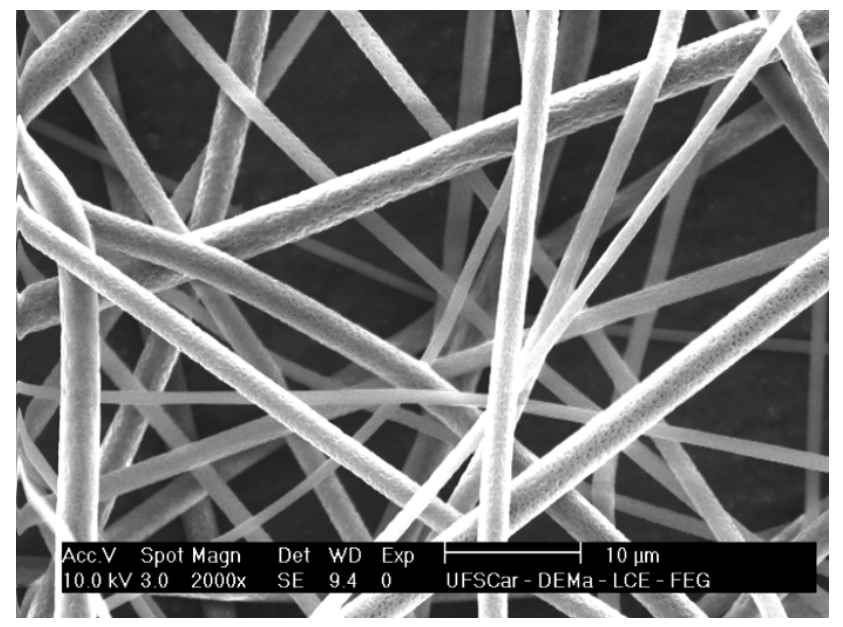

(b)

Figura 2. Micrografias de MEV das nanofibras de PDLLA: a) Amostra 3 e b) Amostra 4.

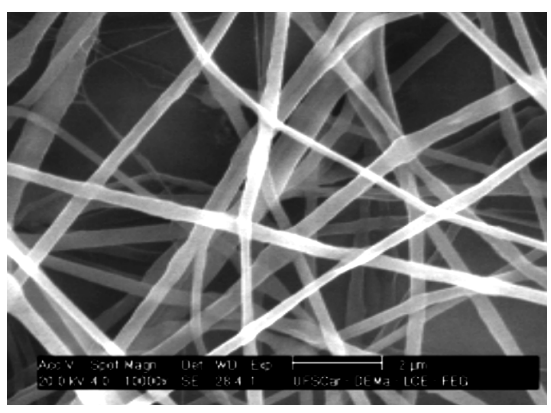

(a)

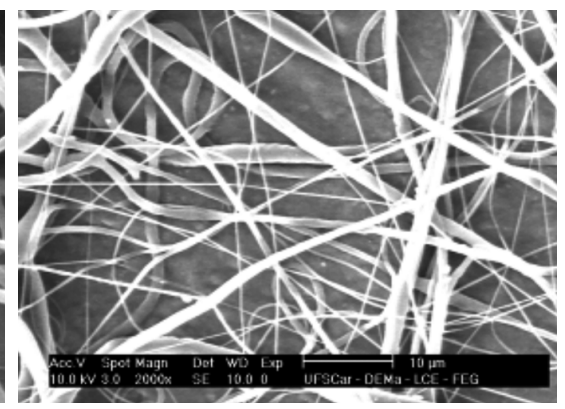

(b)

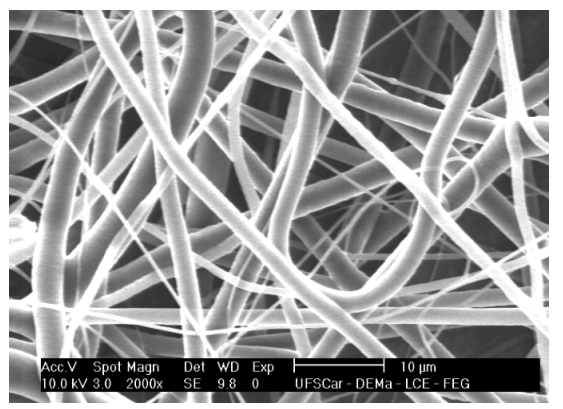

(c)

Figura 3. Micrografias de MEV das nanofibras de PCL: a) Amostra 5, b) Amostra 6 e c) Amostra 7.

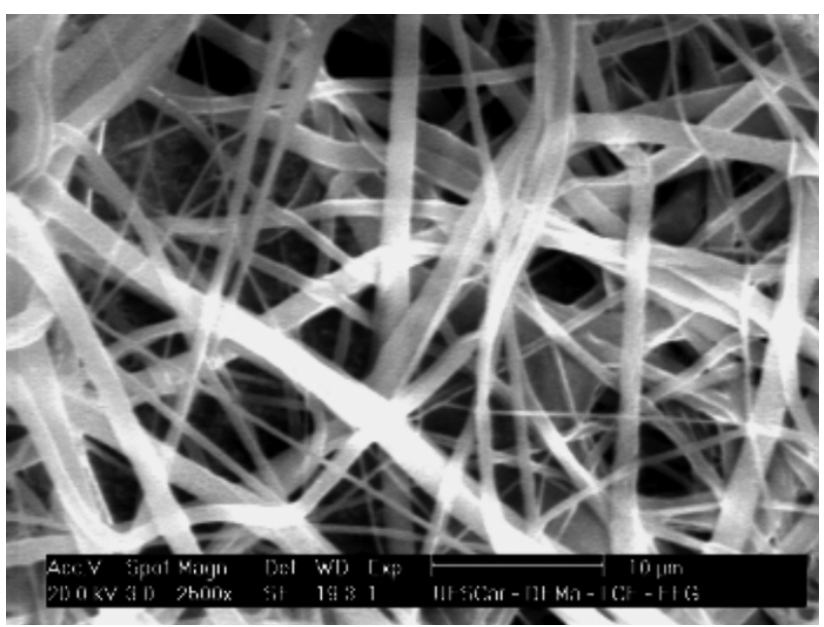

(a)

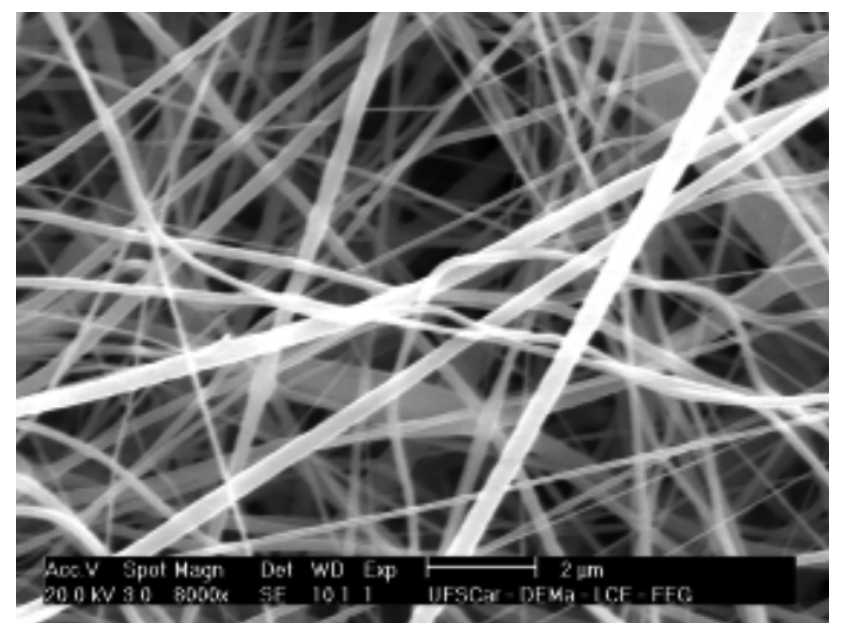

(b)

Figura 4. Micrografias de MEV das nanofibras de PBAT: a) Amostra 8 e b) Amostra 9. 
- Controle positivo: célula + DMEM + soro + PBS (2x);

- Controle negativo: célula + DMEM + soro + lamínulas de vidro;

- População controle positivo: célula + DMEM + soro;

- População controle negativo: célula + DMEM - soro;

- População 3: célula + DMEM + soro + amostra 3;

- População 4: célula + DMEM + soro + amostra 4;

- População 5: célula + DMEM + soro + amostra 5;

- População 6: célula + DMEM + soro + amostra 6;

- População 7: célula + DMEM + soro + amostra 7;

- População 8: célula + DMEM + soro + amostra 8;

- População 9: célula + DMEM + soro + amostra 9.

\section{Resultados}

\section{Caracterização das nanofibras}

As micrografias das amostras 3 e 4 (todas de PDLLA) estão apresentadas na Figura 2. Pode-se observar que as nanofibras da amostra 3 possuem diâmetros médios bem menores do que a amostra 4, como listado na Tabela 2. Porém as nanofibras da amostra 4 são mais porosas ${ }^{[11]}$. As micrografias das amostras 5, 6 e 7 (todas de PCL) são mostradas na Figura 3.

Os resultados da Tabela 2 mostram que as nanofibras do nanocompósito de PCL com montmorilonita (Amostra 5) apresentaram diâmetros médios menores do que as nanofibras de PCL puro, preparadas a concentrações tanto de $15 \% \mathrm{~m} \cdot \mathrm{v}^{-1}$

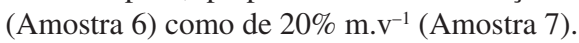

As micrografias de MEV das mantas das amostras 8 e 9 (todas de PBAT) estão apresentadas na Figura 4. Novamente observa-se que o diâmetro médio das nanofibras do nanocompósito de PBAT

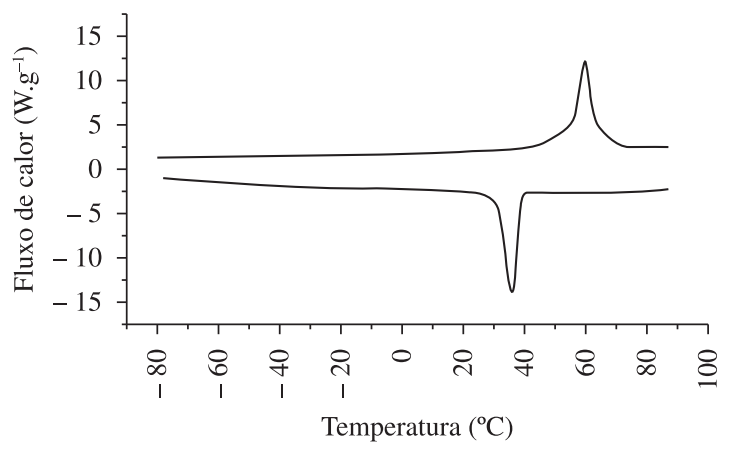

(a)

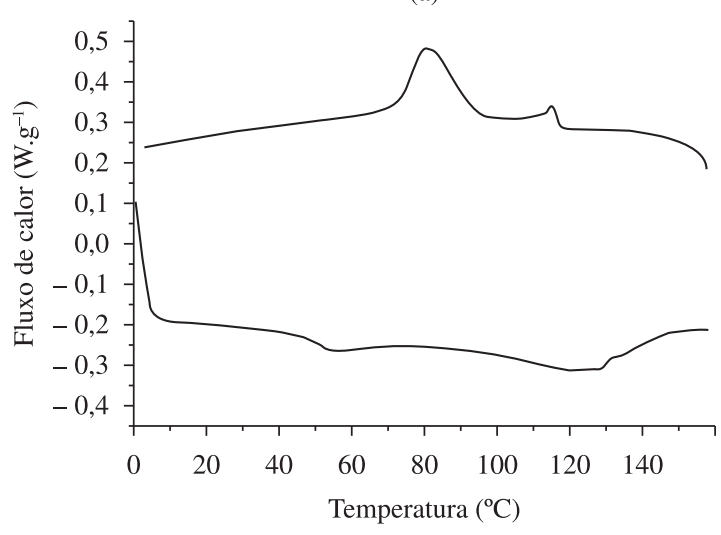

(b)

Figura 5. Termogramas de DSC, curvas de aquecimento e resfriamento, das nanofibras dos nanocompósitos: a) Amostra 5 e b) Amostra 9. com montmorilonita (Amostra 9) é bem menor do que o diâmetro médio das nanofibras de PBAT puro (Amostra 8) como mostrado na Tabela 2, ou seja, a adição da MMT ao PCL e ao PBAT permitiu produzir nanofibras de menor diâmetro e conseqüentemente de maior área superficial de contato.

Os termogramas de DSC, curvas de aquecimento e resfriamento, de algumas das nanofibras estão apresentados na Figura 5.

Todos os termogramas das nanofibras apresentaram uma pequena endoterma perto da temperatura de vaporização dos respectivos solventes, exceto as nanofibras de PCL que foram previamente secas. Esta endoterma foi atribuída à vaporização de solvente residual. A Tabela 3 mostra os valores de solvente residual $\left(\mathrm{X}_{\mathrm{sr}}\right)$ e de cristalinidade $\left(\mathrm{X}_{\mathrm{c}}\right)$ das amostras, calculados a partir destas endotermas.

Observa-se que todas as amostras apresentam baixa quantidade de solvente residual. No caso do PCL, a secagem prévia mostrou-se satisfatória na eliminação de todo resíduo de solvente. Em relação à cristalinidade, observa-se que ambas as amostras de PBAT tiveram a menor cristalinidade entre todas as nanofibras estudadas.

Em relação ao efeito nucleante da MMT observa-se que no caso do PBAT, aparentemente, a MMT não influenciou na cinética de cristalização destas nanofibras; já nas amostras de PCL, as

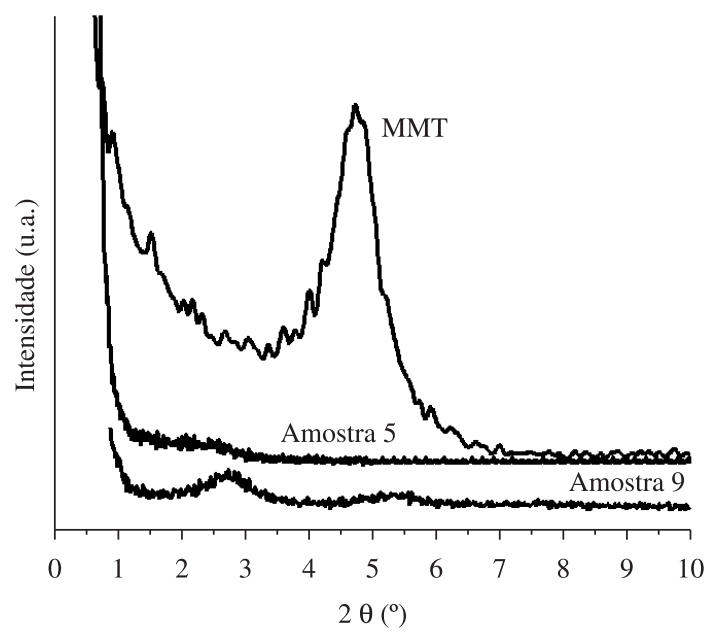

Figura 6. Difratogramas de DRX da argila MMT e das Amostras 5 e 9.

Tabela 3. Quantidade de solvente residual $\left(X_{\mathrm{sr}}\right)$ e cristalinidade $\left(X_{c}\right)$ das nanofibras.

\begin{tabular}{ccc}
\hline Amostra & $\mathbf{X}_{\mathrm{sr}}(\%)$ & $\mathbf{X}_{\mathbf{c}}(\%)$ \\
\hline 3 & $1-2$ & 16 \\
4 & $1-2$ & 16 \\
5 & 0 & $36-42$ \\
6 & 0 & $50-60$ \\
7 & 0 & $50-60$ \\
8 & $1-5$ & $7-12$ \\
9 & $1-5$ & $8-12$ \\
\hline
\end{tabular}

Tabela 4. Valores das distâncias basais $\left(\mathrm{d}_{\mathrm{hkl}}\right)$ da argila na nanofibras de nanocompositos de PCL e PBAT.

\begin{tabular}{ccc}
\hline Material & $\mathbf{2 \theta}\left({ }^{\circ}\right)$ & $\mathbf{d}_{\text {hkl }}(\mathbf{n m}) *$ \\
\hline MMT C30B & 4,70 & 1,88 \\
Amostra 5 & - & $-($ esfoliação) \\
Amostra 9 & 2,74 & 3,22 (intercalação) \\
\hline *Conforme a lei de Bragg: $\mathrm{n} \lambda=2 d_{h k l} \operatorname{sen} \theta ;$ sendo $\mathrm{n}=1 \mathrm{e} \lambda=0,154 \mathrm{~nm}$.
\end{tabular}




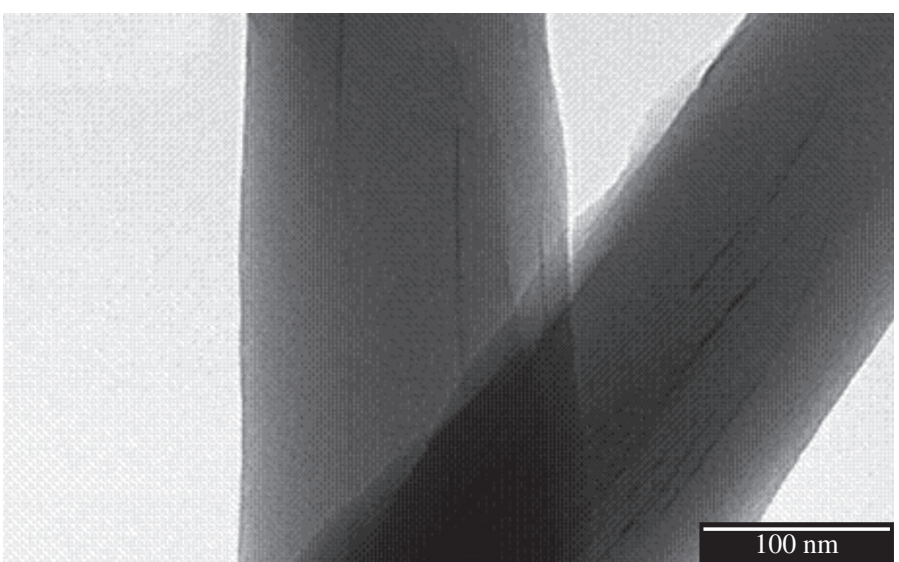

(a)

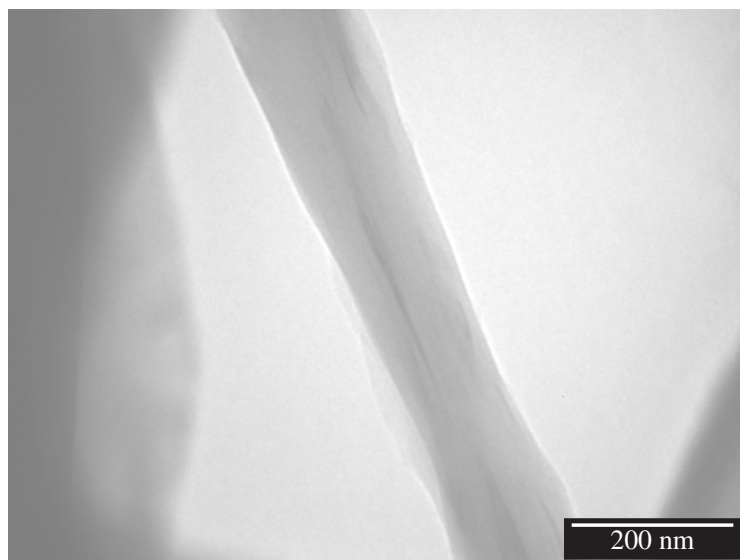

(b)

Figura 7. Micrografias de MET: a) Amostra 5 e b) Amostra 9.

nanofibras do nanocompósito tiveram cristalinidade menor do que as amostras puras, sugerindo interferência da MMT na cristalização do PCL.

As análises de DRX da MMT e das nanofibras dos nanocompósitos de PCL e PBAT estão apresentadas na Figura 6.

Estes difratogramas mostram que a MMT apresentou estrutura esfoliada no nanocompósito com PCL e estrutura intercalada no nanocompósito com PBAT. A Tabela 4 mostra os valores das distâncias basais $\left(\mathrm{d}_{\mathrm{hkl}}\right)$ nos nanocompósitos de PCL e PBAT calculadas destes difratogramas.

As micrografias de MET das amostras 5 e 9 mostradas na Figura 7 permitem que tactóides e lamelas da MMT sejam observadas, principalmente na superfície das nanofibras, confirmando seu efeito plastificante. Estes resultados estão de acordo com os resultados de DRX apresentados acima.

\section{Viabilidade celular}

Como descrito acima, o ensaio de MTT analisa quantitativamente a redução do sal de tetrazolium (MTT) pelo complexo enzimático piruvato desidrogenase presente nas mitocôndrias com a formação de um produto final de cristais de formazan que são mensurados em espectrofotômetro a $595 \mathrm{~nm}$. Esse ensaio é usado especificamente para a funcionalidade mitocondrial e avalia a toxicidade do material através da viabilidade celular. Todas as amostras quando em contato com os dois tipos celulares não apresentaram toxicidade na análise da viabilidade celular no ensaio de MTT (Figuras 8 e 9). Na Figura 8 é possível observar o gráfico comparativo da viabilidade celular das populações celulares em contato direto com as amostras 3, 4, 5, 6, 7, 8 e 9 em relação ao grupo controle utilizando a técnica do MTT. Observa-se no gráfico que as células SkHep quando em contato com as amostras apresentaram índice de toxicidade abaixo de 50\% e não apresentaram diferença percentual de viabilidade quando comparadas com o grupo controle no ensaio de MTT. As células quando em contato com as amostras 5 e 6 apresentaram um índice de viabilidade menor quando comparadas com as outras amostras, porém estatisticamente essa diferença não foi significativa (análise estatística- $t$ test/ GraphPad Prism).

A Figura 9 apresenta o gráfico comparativo da viabilidade celular das populações celulares de fibroblastos de cardiomiócitos em contato direto com as amostras $3,4,5,6,7,8$ e 9 em relação ao grupo controle utilizando a técnica do MTT. Observa-se neste gráfico que as células quando em contato com as amostras 2, 3, 4, 5, 6 e 7 não apresentaram diferença percentual significativa de

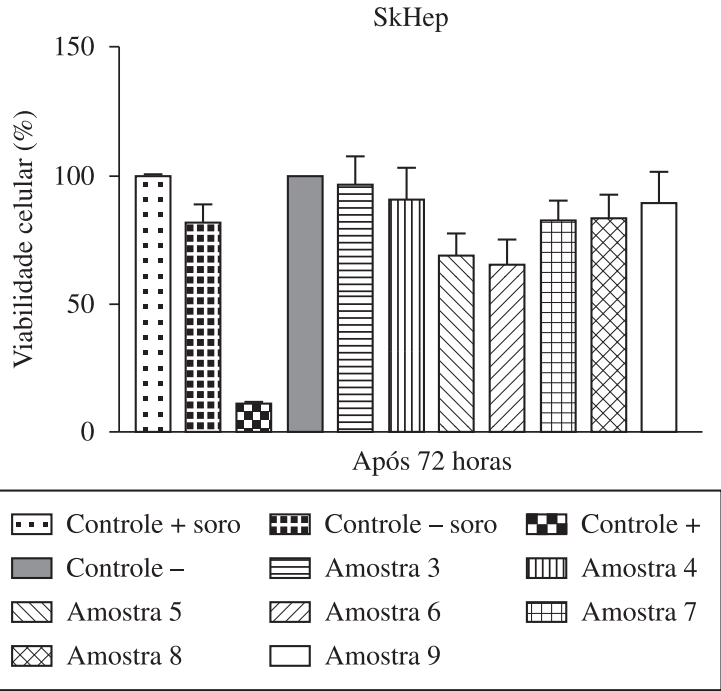

Figura 8. Viabilidade celular de SkHep através do ensaio de MTT.

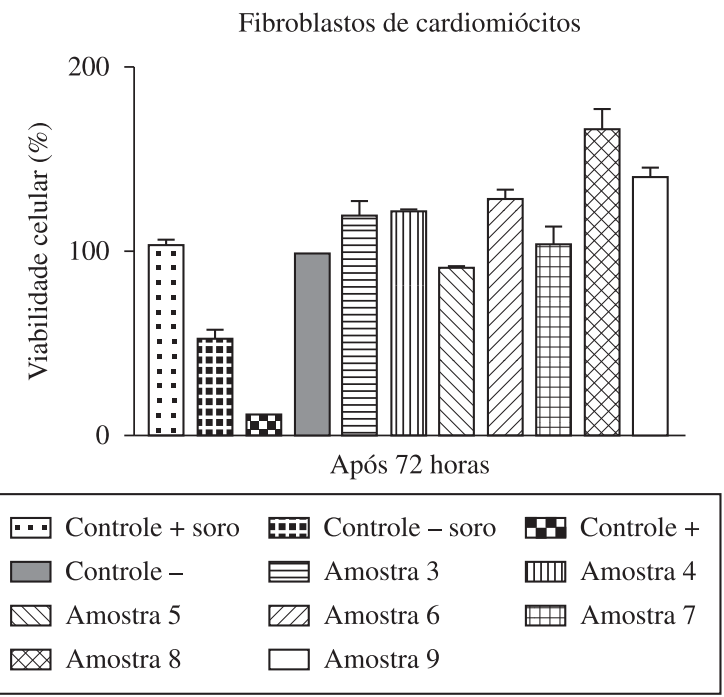

Figura 9. Viabilidade celular de fibroblastos de cardiomiócitos através do ensaio de MTT. 
viabilidade quando comparadas com o grupo controle. As amostras 8 e 9 apresentaram, porém, uma diferença percentual significativa de aproximadamente $50 \%$ e $30 \%$ acima do grupo controle, respectivamente, com $\mathrm{p}<0,001$ para amostra 8 e $\mathrm{p}<0,05$ para amostra 9 (análise estatística- $t$ test/ GraphPad Prism). As mantas das amostras 8 e 9 apresentaram nanofibras de menor diâmetro e de maior área superficial de contato. Este fato possivelmente propiciou um ambiente mais favorável à fixação e ao desenvolvimento dos fibroblastos de cardiomiócitos.

Através dos ensaios de viabilidade celular pôde ser observado que a quantidade de solvente residual observado nas nanofibras é tolerável, não representando toxidez às células, assim permitido à fixação e ao desenvolvimento dos fibroblastos de cardiomiócitos.

\section{Conclusões}

Nenhuma das nanofibras eletrofiadas dos polímeros biodegradáveis PDLLA, PCL e PBAT (Amostras 3, 4, 5, 6, 7, 8 e 9) apresentou toxicidade às células SkHep e aos fibroblastos de cardiomiócitos nos ensaios de viabilidade celular por MTT. As amostras 8 e 9 (nanofibras de PBAT e nanocompósito de PBAT com MMT, respectivamente) propiciaram ainda um ambiente mais favorável ao desenvolvimento celular de fibroblastos de cardiomiócitos do que as condições oferecidas pelo controles, provavelmente por apresentarem menores diâmetros e baixa cristalinidade em relação às demais nanofibras. A quantidade de solvente residual nas nanofibras não representa toxidade às mesmas. Estes resultados mostram o potencial de uso destas mantas nanofibrilicas como suportes de crescimento celular.

\section{Agradecimentos}

Os autores agradecem à FAPESP, ao CNPq e a CAPES/Cofecub pelo apoio financeiro, ao Eng. Julio Harada da BASF pela doação do PBAT e ao Prof. Rinaldo Gregório Filho pelo empréstimo da fonte de alta tensão.

\section{Referências Bibliográficas}

1. Formhals, A. - "Process and apparatus for preparing artificial threads", USA Patente 1.975.5042 (1934).
2. Nel, A.; Xia, T.; Maddler, L. \& Li, N. - Science, 311, p.622 (2006). PMid:16456071. http://dx.doi.org/10.1126/science.1114397

3. Lee, Y. H.; Kuo, T. F.; Chen, B. Y.; Feng, Y. K.; Wen, Y. R.; Lin, W. C. \& Lin, F. H. - Biomed. Eng. Appl., Basis, Commun., 17, p.12 (2005).

4. Baker, S. E.; Sawvel, A. M.; Zheng, N. \& Stucky, G. D. - Chem. Mater., 19, p.4390 (2007). http://dx.doi.org/10.1021/cm071457b

5. Coleman, N. J.; Bishop, A. H.; Booth, S. E. \& Nicholson, J. W. - J. Eur. Ceram. Soc., 29, p.1109 (2009). http://dx.doi.org/10.1016/j. jeurceramsoc.2008.08.015

6. Haydel, S. E.; Remenih, C. M. \& Williams, L. B. - J. Antimicrob. Chemother., 61, p.353 (2008). PMid:18070832. PMCid:2413170. http://dx.doi.org/10.1093/jac/dkm468

7. Li, P-R.; Wei, J-C.; Chiu, Y-F.; Su, H-L.; Peng, F-C. \& Lin, J-J. Appl. Mater. Interfaces, 2, p.1608 (2010). http://dx.doi.org/10.1021/ am1001162

8. Shah, P. N.; Manthe, R. L.; lopina, S. T. \& Yun, Y. H. - Polymer, 50, p.2281 (2009). http://dx.doi.org/10.1016/j.polymer.2009.02.048

9. Schifman, J. D. \& Schauer, C. L. - Polym. Review, 48, p.317 (2008).

10. Pimenta, J. G.; Branciforti, M. C.; Avérous, L. \& Bretas, R. E. S. - "Preparation and Characterization of Poly(E-caprolactone) Nanofibers", in: Anais do $23^{\circ}$ Annual Meeting of the Polymer Processing Society, Salvador, Brasil (2007).

11. Branciforti, M. C.; Custódio, T. A.; Guerrini, L. M.; Averous, L. \& Bretas, R. E. S - J. Macrom. Sci, Part B: Phys., 48, p.1222 (2009).

12. Guerrini, L. M.; Branciforti, M. C.; Oliveira, M. P. \& Bretas, R. E. S. - Polímeros, 16, p.286 (2006). http://dx.doi.org/10.1590/S010414282006000400007

13. Martin, O. \& Avérous, L. - Polymer, 42, p.6209 (2001). http://dx.doi. org/10.1016/S0032-3861(01)00086-6

14. Chivrac, F.; Kadlecová, Z.; Pollet, E. \& Avérous, L. - J. Polym. Environ, 14, p.393 (2006). http://dx.doi.org/10.1007/s10924-0060033-4

15. Gädda, T.; Kylmä, J.; Tuominen, J.; Mikkonen, H.; Lain, A.; Peltonen, S. \& Seppälä, J. - J. Appl. Polym. Sci., 100, p.1633 (2006). http:// dx.doi.org/10.1002/app.23697

Enviado: 24/09/10

Reenviado: 27/01/11

Aceito: 29/04/11 